\title{
CERRADO KNOWLEDGE PLATFORM: A SOCIAL AND ENVIRONMENTAL MANAGEMENT TOOL TO CONSERVE BRAZILIAN SAVANNAS
}

\author{
M. E. Ferreira ${ }^{1}$, E. B. Silva ${ }^{1}$, F. S. S. Malaquias ${ }^{1}$, L. M. S. Teixeira ${ }^{1}$, L. M. Pascoal ${ }^{1}$, N. B. Santos ${ }^{1}$, T. F. Oliveira ${ }^{1}$
}

${ }^{1}$ Image Processing and Geoprocessing Laboratory (LAPIG) - Federal University of Goiás, Goiânia - GO, Brazil

(mferreira.geo, elainesilvaufg, fer.stefani.souza, lanamarast, luizmlpascoal, nataliabarrosufg, thaisafernandesciamb)@gmail.com

KEY WORDS: Spatial database, Environmental policies, Critical Ecosystem, Biodiversity conservation, Deforestation, UAV images.

\begin{abstract}
:
In the last decade, the access to geographic information through Web platforms has grown substantially in Brazil, and is now a strategic condition for the social and environmental governance of large biomes such as Cerrado (savanna) and Amazonia. This paper aims to present the first version of the Cerrado Knowledge Platform, designed within the scope of the Critical Ecosystem Partnership Fund (CEPF) for the Brazilian savanna. The Platform aims to provide geospatial and census data, organize and systematize the accumulated knowledge about the Cerrado, and also highlight the actions of researches and social networks in this region. It was developed based on three components: (1) protocols and data formats; (2) adaptation of computational tools for social and environmental analysis and monitoring, in order to notify possible threats to the ecosystem (e.g. burning and deforestation); (3) training and maintenance database component. Although still in a beta version, our platform already has some active features, including access to dynamic land use maps, deforestation, and aerial imagery provided by Unmanned Aerial Vehicles (UAVs). With its enhancement and constant data input from partners, we expect the Cerrado Knowledge Platform can better assist the management of land use and land cover of Cerrado, with a perspective of maintaining key areas for biodiversity conservation.
\end{abstract}

\section{INTRODUCTION}

In Brazil, a continental country and owner of six large ecosystems - especially the Amazon (of recognized international value) and the Cerrado (the largest and most biodiverse tropical savanna in the world), rapid access to geographic information becomes a strategic condition for social and environmental management. About 10 years ago, Web platforms started to become popular in the country, although restricted to governmental initiatives led, for example, by public agencies such as IBGE (Brazilian Institute of Geography and Statistics), INPE (National Institute for Space Research), MMA (Ministry of the Environment), ANEEL (National Electric Energy Agency) and ANA (National Water Agency) (Castro \& Ferreira, 2012).

More recently, with multi-institutional efforts provided mainly by research groups based in national and foreign universities, foundations and NGOs, the number of web platforms has grown substantially, providing a new level of experience for the society. This fact is linked to the transparency of public information and new computational languages / tools, especially those of open source code, with which the availability and online representation of large geographic databases became possible, since satellite / aerial databases (and their products derived through classifications) to deforestation, burning and socioeconomic maps. Examples of these efforts in Brazil and in the world are found at Pastagem.org (https://pastagem.org), MapBiomas (http://mapbiomas.org), TerraBrasilis (http://terrabrasilis.dpi.inpe.br), Trase (https://trase.earth), and Global Forest Watch (https://www.globalforestwatch.org), bring temporal maps of land use, quality pastures mapping, deforestation features in Cerrado and Amazon biomes, agribusiness production chains, and $\mathrm{CO}_{2}$ emissions in forests, respectively.

Regarding to Brazilian ecosystems, several studies have demonstrate a positive effect of platforms on natural resource management and biodiversity, especially for policy makers and decision makers (Parente et al., 2013; Campos et al., 2017; Malaquias et al., 2017; Ferreira et al., 2019). In Cerrado biome, focus area of this work, its coverage - spread over 11 Brazilian states over 2 million $\mathrm{km}^{2}$-, high biological richness, and the real threat of extinction due to the intense conversion to agricultural activities, exposed the need for a broader data platform, as well as integrative, able to guide public policies and actions for nature preservation. Recent data indicate a conversion rate of this biome in the order of $50 \%$ (MapBiomas, 2019), with unenthusiastic future scenarios, pointing out to a reduction of water (in terms of quality and quantity) in the next three decades, besides an irreparable loss of endemic flora and fauna of this region (Ferreira et al. 2013; Latrubesse et al. 2019).

In this context, within the scope of the Critical Ecosystem Partnership Fund (CEPF), which elected the Cerrado as one of the critical areas for biodiversity conservation, the project Cerrado Knowledge Platform was derived, focused exclusively on spatial database and data access, while open to contributions from similarly oriented research institutions or groups, supported by CEPF between 2016 and 2021 (more information at https://www.cepf.net).

In addition to organizing and systematizing the accumulated knowledge about the Cerrado, this platform has the potential to highlight the actions of a countless research and social action networks, meeting the demands of traditional communities, including indigenous, quilombolas and riverside people, which currently have little or no insertion in the debate between the exploitation and preservation of natural resources. With such an instrument, these communities will be able to consult and contribute to the advancement of knowledge by sharing their traditions, and acting as advocates of local ecosystems, through threat notifications such as fire and illegal deforestation alerts.

Thus, the main objective of this paper is to present the beta version of the Cerrado Knowledge Platform, released for testing in November 2019 (http://cepf.lapig.iesa.ufg.br), which is expected to share data, information and knowledge among the 
institutions directly involved with Cerrado biome (whether or not related to CEPF initiatives in Brazil), with a perspective to engaging organized society with reliable information, monitoring tools and geographic analysis.

\section{MATERIALS AND METHODS}

\subsection{Study Area}

Our study area covers the entire Cerrado biome (Figure 1), taking into account the availability and comprehensiveness of geographic data generated by partner institutions to be incorporated into the Cerrado Knowledge Platform.

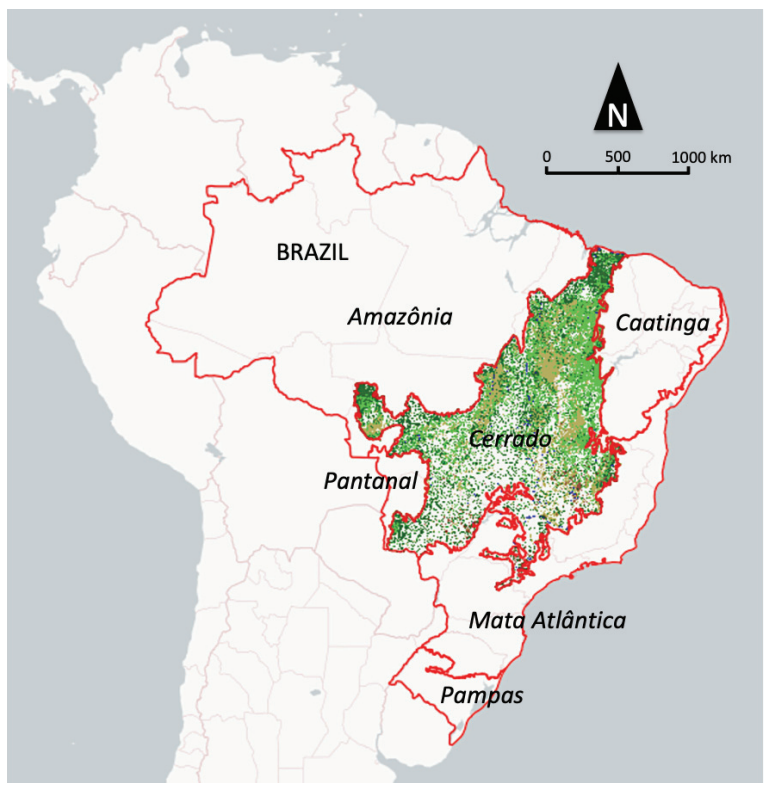

Figure 1. Study area encompassing the entire Cerrado biome, with emphasis on the land cover map in 2018 (MapBiomas, 2019) and the boundaries of other Brazilian biomes. Blank areas within the Cerrado map indicate the presence of agriculture and pasture $(\sim 50 \%)$.

\subsection{Methodological procedures}

Our project is structured in the following components and procedures:

- Component 1: Compilation of available databases (public or private), selection and organization of raster and vector data generated by major biome-related initiatives (see Tables 1 and 2). The platform already considers, for instance, data from the TerraClass Cerrado, PRODES - Cerrado and MapBiomas (exemplified in Figure 1) projects, as well as the Agricultural Census and the Municipal Agricultural Research.

In this component (1), the following steps are highlighted: (a) Definition of protocols and data formats, filtering the information encompassing the Cerrado biome, according to the demands presented by the partner institutions, or other projects contemplated by the CEPF - Cerrado; (b) Definition and compatibility of formats, assessing the guidelines presented by IBGE / CONCAR (National Cartography Commission) regarding formats (vector, raster and tabular) and cartographic parameters; consult with INDE (National Spatial Data Infrastructure) regarding availability, metadata and geospatial information (i.e., spatial data standardization for online platforms); (c) Identification of key geographic database providers that meet Open Geospatial Consortium (OGC) protocols, known to employ services such as Web Map Service (WMS), Web Feature Service (WFS), and Web Coverage Service (WCS). These services will be required to make data available on the online platform for viewing and downloading, vector formats (maps), images (satellite / aerial mosaics and spatial modeling), and tables / graphics (alphanumeric); (d) Definition of data transfer mechanisms: implement a virtual environment for sending and receiving geographic data to be made publicly available on the portal upon request.

\begin{tabular}{|c|c|c|}
\hline Institution & Theme & Type \\
\hline ICMBio* $^{*}$ & Geopolitical & Conservation units \\
\hline LBDS** & $\begin{array}{c}\text { Cerrado Land use } \\
\text { mapping \& deficit of } \\
\text { Permanent Preservation } \\
\text { Areas }\end{array}$ \\
\hline $\begin{array}{c}\text { FIP Cerrado*** } \\
\text { DPAT }\end{array}$ & Land use & Deforestation \\
\hline $\begin{array}{c}\text { Instituto Oca } \\
\text { Brasil }\end{array}$ & Geopolitical & $\begin{array}{c}\text { Permanent Preservation } \\
\text { Areas analysis }\end{array}$ \\
\hline IBGE & Land Use & Agricultural census data \\
\hline Agrosatélite & Land Use & $\begin{array}{c}\text { Cotton, corn and soy } \\
\text { mapping }\end{array}$ \\
\hline LAPIG & Land Use & $\begin{array}{c}\text { Pasture mapping \& } \\
\text { degradation level }\end{array}$ \\
\hline
\end{tabular}

Table 1. Examples of Cerrado Knowledge Platform contributors from government and NGOs. *Instituto Chico Mendes de Conservação da Biodiversidade; **Brazilian Foundation for Sustainable Development; *** Monitoramento do Cerrado Project / MCTIC / World Bank.

\begin{tabular}{|c|c|}
\hline Category & Quantity \\
\hline Water & 3.082 \\
\hline Infrastructure & 49 \\
\hline Land Use & 73 \\
\hline Pasture & 329 \\
\hline Others & 1.252 \\
\hline Agriculture & 713 \\
\hline Relief & 27 \\
\hline Geopolitical & 53 \\
\hline Social & 195 \\
\hline Deforestation & 170 \\
\hline Vegetation & 4.959 \\
\hline Satellite Images & 18 \\
\hline
\end{tabular}




\begin{tabular}{|c|c|}
\hline Soil & 6 \\
\hline Aerial Images & 76 \\
\hline Burnings & 46 \\
\hline Biodiversity & 3 \\
\hline Total & $\mathbf{1 1 . 0 4 9}$ \\
\hline
\end{tabular}

Table 2. Current quantitative (by category) of spatial database already available for the Cerrado Knowledge Platform

(November 2019).

- Component 2: Responsible for the requirement analysis, development, testing and adequacy of computational tools that will compose the Cerrado Knowledge Platform. Two public tools are been developing, one for data availability and analysis, and another for historical monitoring of this ecosystems. The first one will be responsible for providing a unified and organized view of the resulting database from component 1 , enabling stakeholders and other users to search, view and perform social and environmental analyzes through a free public web portal. Such analyzes may be carried out by various study units, such as location of rural properties, boundaries of municipality, state, watershed, protected areas, etc. The monitoring tool will allow members of traditional communities and other sectors of civil society to issue notifications of threat to ecosystems, warnings as fire events, activities that compromise the quality of water resources, likewise any practice of degradation of natural resources in the Cerrado biome. The steps of this component are as follows: (a) Tool for data availability and analysis, including visualization (georeferenced maps and images), time series analysis, logistic analysis, vectoring, among others defined by partners, including specific applications for smartphones or tablets; (b) Development of features for data availability (i.e. preparing tools for viewing and downloading); (c) Development of dashboard for visualization of statistical data (i.e., visualization screen with all requested data, integrated / overlapping with specific subtitles and standardized scale); (d) development of a module for territorial analysis, with a tool for integrated analysis of a region / territory, with physical, political and socioeconomic data, aiming to guide decision making more efficiently; (e) Maintenance of the functionalities through support by the development team, maintaining the portal, adjusting tools and databases on an ongoing basis.

- Component 3: responsible for building and maintaining the portal / database, articulating with stakeholders the use of the databases and tools resulting from components 1 and 2, also providing long term project maintenance. From 2020, training actions will be held, with lectures and practical workshops in public agencies (e.g. environmental and rural agencies, associations and agricultural entities, etc.), universities, local communities, in order to reach as many social organizations, traditional communities and government institutions as possible.

Concerning the architecture of our platform, it is client-server type, where the client application (Web Map Client) communicates with the HTTP server (HTTP Server) (Figure 2). The client application is responsible for the visualization of data and information, developed with "Angular" - a web application platform (Framework), and "OpenLayers" - an API for displaying interactive map data in web browsers, communicating with an HTTP server (HTTP Server) using Apache, responsible for providing pages and all resources that can be accessed by the client application, while the application server is Node.js, responsible for accessing the database and consolidating the data that will be presented to the customer.

Mapserver, the solution responsible for presenting spatial data on the Web, enable the construction and visualization of geographic maps through the Tile Map Service (TMS) protocol, already consolidated in several WEBGIS solutions. For data storage, we opted for PostGIS, a spatial extension built on the PostgreSQL database management system, which allows the use of Geographic Information Systems (GIS) structures and operations directly in the database. All technologies used here are open source type and can be modified by any user or institution (Figure 2)

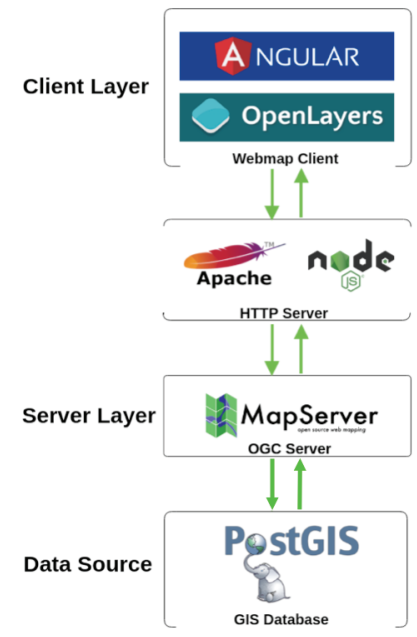

Figure 2. Computational architecture of the Cerrado Knowledge Platform based on free and open source software.

\section{RESULTS AND DISCUSSIONS}

The Cerrado Knowledge Platform is already up and running (beta version for testing), with some functionalities, including access to dynamic land use and land cover maps, deforestation and aerial imagery provided by Unmanned Aerial Vehicles (UAVs). Figure 3 illustrates the general aspects of the Platform, highlighting the sub-platforms "deforestation", "aerial images (UAV)", "land use", "biodiversity", "socio-environmental" and "academic/scientific literature".

It will give us visibility to the results produced by the various projects supported by CEPF, as well as by other initiatives, consolidating a relevant knowledge about the Cerrado biome. With such an instrument, it is expected that the government sector will use it to formulate and monitor public policies, likewise Forest Code and Rural Environmental Registry. Considering the results to be obtained by partners, such as MMA / Ibama, MCTIC / INPE (via PRODES Cerrado), and NGOs such as TNC, CI Brazil, WWF, ISPN and IPAM, this platform will have the potential to better guide the expansion of new areas for agriculture and livestock, with a view to maintaining important portions of native vegetation (environmental assets), considering key conservation areas, and minimizing anthropic pressure on biodiversity and traditional communities. This kind of analysis is 
need for "zero deforestation" policies in the near future, in balance with the growing demand for food and water.

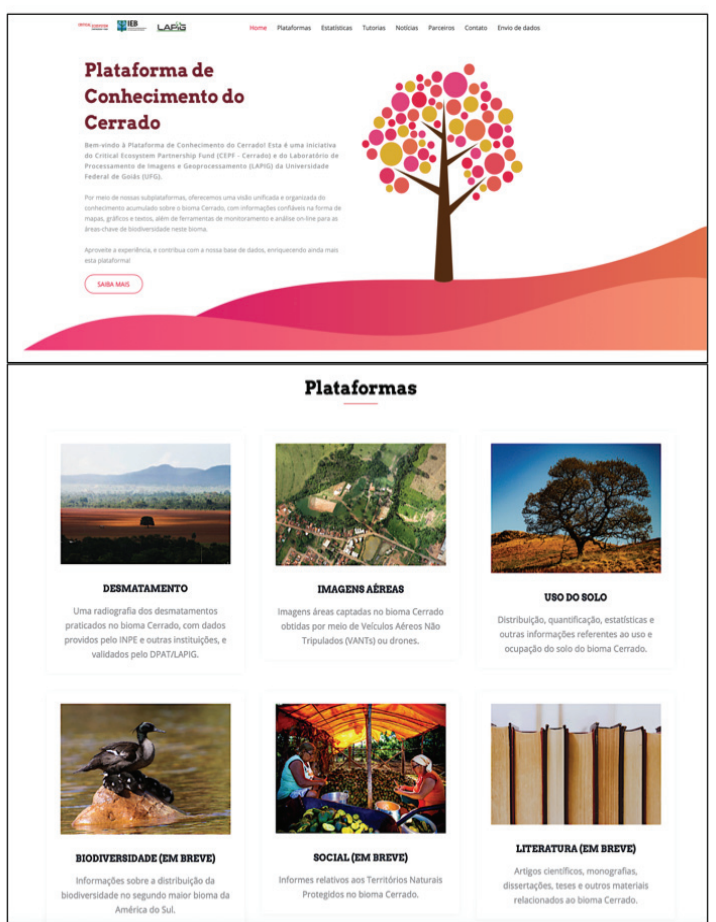

Figure 3. Overview of the Cerrado Knowledge Platform, accessed through the link $<$ https://cepf.lapig.iesa.ufg.br $>$.

Figures 4, 5 and 6 illustrate the sub-platforms already in operation in the Cerrado Knowledge Platform, highlighting, respectively, the current pasture map (2018) and intensification charts of this sector, followed by the temporal distribution of deforestation in the biome (via INPE / PRODES and DETER warning deforestation systems), and UAVs orthorectified and georeferenced mosaics in the Cerrado. All data can be downloaded directly from the portal at no cost or registration, allowing as well as uploads of images, maps and documents by any person or institution by filling out our metadata form.

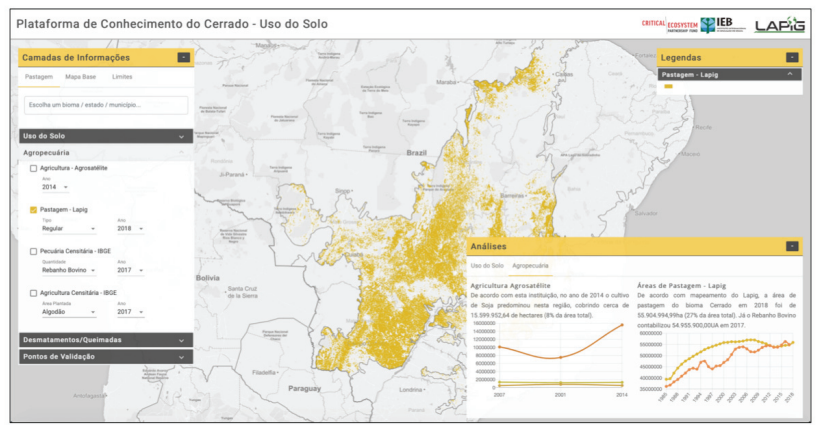

Figure 4. General aspect of the "land use" sub-platform, highlighting the Cerrado pasture map (from 2018), with respective expansion and intensification graphs (cattle herd).

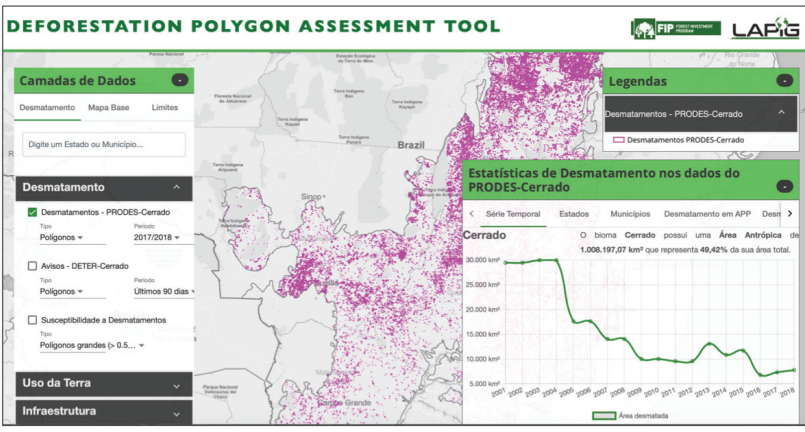

Figure 5. Overview of the "deforestation" sub-platform, highlighting the deforestation polygons provided by INPE, with validation support by the Deforestation Polygon Assessment Tool (DPAT / LAPIG).

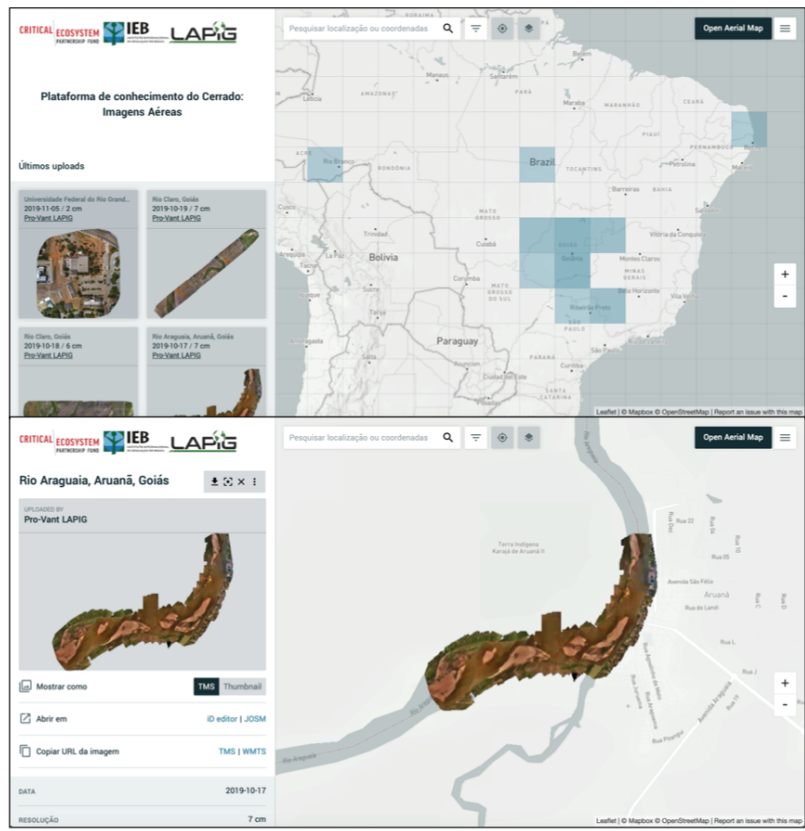

Figure 6. General aspect of the "aerial images" sub-platform, highlighting the search and download module of orthorectified mosaics for sample areas in the Cerrado biome. The open source code was adapted from the Open Aerial Map platform.

\section{CONCLUSIONS}

In the medium and long term, it is expected from the Cerrado Knowledge Platform the following advances:

1) Gradual reduction of environmental impacts (e.g., loss of fauna and flora species, deforestation and burnings), a better knowledge of this territory, likewise a greater engagement of organized civil society, supported by direct and indirect actions within CEPF initiatives;

2) Consolidation and dissemination of knowledge about the Cerrado biome, through a dedicated and reliable data platform, also promoting the permanent visibility of products generated by other CEPF-supported research groups. 
3) Subsidies for the creation and better manager of Conservation Units in the Cerrado, in compliance with the Brazilian Forest Code (e.g., legal reserves and Permanent Preservation Areas along rivers) and the reforestation goals of degraded areas, while indicate weaknesses and gaps in our knowledge.

4) Dynamic and up-to-date management of the Cerrado's natural resources, allowing for a faster return to traditional community conservation and empowerment initiatives.

5) Availability of cartographic data and spatial analysis tools for all sectors of society, providing resources for the diagnosis and mitigation of social and environmental impacts.

6) Better control of the Cerrado's environmental assets, especially the remnants of vegetation, soils and hydrography.

\section{ACKNOWLEDGEMENTS}

We thank to the Critical Ecosystem Partnership Fund (CEPF) for providing scholarships, equipment and participation in this scientific event. Thanks are extended to our partners for the availability of spatial information on the Cerrado Knowledge Platform.

\section{REFERENCES}

Campos, W. S.; Ferreira, M. E.; Teixeira, L. M. S.; Malaquias, F. S. S.; Parente, L. L.; Ferreira, L. G., 2017. Plataforma livre e interativa de mapas para a gestão territorial e ambiental do bioma cerrado. Revista Brasileira de Cartografia, v. 69, p. 1598-1609.

Castro, W.; Ferreira, M. E., 2017. Bases de dados geográficas digitais no Brasil: formatos, acessibilidade e aplicações. Ateliê Geográfico, vol. 6, n. 1, p. 92-122, 2012. DOI 10.5216/ag.v6i1.18764

Ferreira, M. E.; Ferreira, L. G.; Miziara, F.; Soares-Filho, B. S., 2013. Modeling landscape dynamics in the central Brazilian savanna biome: future scenarios and perspectives for conservation. Journal of Land Use Science, v. 8, p. 403 - 421.

Ferreira, M. E.; Silva, B. E.; Malaquias, S. S. F. ; Teixeira, L. M. S. et al., 2019. Plataforma de conhecimento do Cerrado: uma proposta de gestão para um bioma crítico e ameaçado. In: Anais do XIX Simpósio Brasileiro de Sensoriamento Remoto, Santos. Available in: $\quad<$ https://proceedings.science/sbsr2019/papers/plataforma-de-conhecimento-do-cerrado--umaproposta-de-gestao-para-um-bioma-critico-e-ameacado $>$. Access in: $10^{\text {th }}$ November 2019.

Latrubesse, E. M.; Arima, E.; Ferreira, M. E.; Nogueira, S. H. M.; Wittmann, F.; Dias, M. S.; Dagosta, F. C. P.; Bayer, M., 2019. Fostering water resource governance and conservation in the Brazilian Cerrado biome. Conservation Science and Practice, v. 1, p. $1-8$.

Malaquias, F. S. S.; Teixeira, L. M. S.; Santiago, R. B. S.; Parente, L. L. e Ferreira, L. G, 2017. Pastagem.org: dados e informações para uma compreensão ambiental, econômica e social sobre a última fronteira agrícola do Brasil, em Anais do XVIII Simpósio Brasileiro de Sensoriamento Remoto. Santos - SP, Brasil, pp. 1392-1399.
MapBiomas, 2019. Available in:

$<$ http://mapbiomas.org $>$. Access in: $28^{\text {th }}$ November 2019.

Parente, L. L.; Medeiros, L. C.; Ferreira, L. G.; Ferreira, M. E., 2013. Uma plataforma de pesquisa para o Cerrado: disseminando e promovendo dados e conhecimento científico sobre um bioma ameaçado. In: Anais do XVI Simpósio Brasileiro de Sensoriamento Remoto. INPE/SBSR: Foz do Iguaçu, PR, Brasil, p. $2509-2516$. 